\title{
The Impact of Literature Circles on the Motivation of Turkish EFL Students towards Literature: An Evaluation of Teachers' Perceptions*
}

\author{
Nilay Avcı ${ }^{1}$
}

Çă̆ University, Mersin, Turkey

\section{Abstract}

Submitted

19.02.2019

This study aims to determine why teachers prefer implementing literature circles. It also aims to discover if the literature circle helps students' comprehension of literature and language and how it affects students' attitudes towards reading through teachers' perceptions. Along with the presence, implementation and effect of literature circles in education, processes and changes that students go through while taking part in the circles based on selected literary works were investigated. When the data gathered through interviews with circle teachers were analysed, it supported the view that use of literature circles clearly helps students to understand literature better by increasing their desire to read. Additionally, the view that students' general attitudes towards reading change positively after taking part in the circles was supported by the results. The results also emphasized that students can develop better comprehension techniques in the circles which will enable them to use the literature for authentic and meaningful purposes.

Revised

17.04.2019

Accepted

05.05.2019

Keywords:

literature circles, student-centred education, teaching literature, reading activities, student attitudes, teacher perceptions

\section{Suggested Citation:}

Avcl, N. (2019). The Impact of Literature Circles on the Motivation of Turkish EFL Students towards Literature: An Evaluation of Teachers' Perceptions, International Journal of Academic Research in Education, 4(1-2), 1-18. DOI: 10.17985/ijare.529371

\footnotetext{
*This article is based partly on master's thesis supervised by Assist. Prof. Dr. Kim Raymond Humiston.

${ }^{1}$ Lecturer, Çă̆ University, Faculty of Arts and Sciences, Department of English Language Teaching. nilayavci@ cag.edu.tr
} 


\section{INTRODUCTION}

Most English language learners describe reading as a boring or difficult activity. Nevertheless, it is considered as a vital element of language learning. Işıklı and Tarakçığlu (2017) summarises the problems in EFL literature teaching during its practical applications as "students' low levels of proficiency in English, teacher incompetence, low motivation, lack of confidence, limited resources, lack of materials etc.". Generally, reading or literature classes are the least favourite, most hated or the most difficult courses for students at any age. Because reading is a "complex and multifaceted" activity as Demiröz (2010) emphasises, most of the students do not like to read the required assessments for a course. They all hate even the idea of assigned readings and homework. They do not want to actively engage in reading and discussion activities in the classroom. It is quite easy to lose track when they do not attend the structured lectures. Tevdovska (2016) points out the difficulty and complexity of understanding the language used in literature and also cultural concepts which are unfamiliar for the students. According to Parkinson and Reid Thomas (2000) "like other learning materials, literary texts can be so difficult that learners do not understand them or understand them only by dint of time consuming and wearisome dictionary work" ( $p$. 12). As a result of this, most of the time they come to class unprepared. Even if they do all the assessments and try to participate in the discussions, they see it as a requirement for passing the class which they are forced to do. Therefore, unsurprisingly, as they are not doing the assessments for the sake of doing it, it does not effectively work out. The students feel bored and sleepy. They simply try to retell the stories without changing the original sentences. Most of the comments are unrelated. It is because "although they can understand the literal meaning of a text, they do not seem to have the critical thinking skills to analyse and interpret the texts or identify their messages and themes" (Ghazali, 2008). Some of them just listen, but are not willing to participate and avoid direct eye contact with the teacher. The whole-class discussions become a torture. As most of them do not have an idea, they feel they have little or nothing to add to the discussion. Some of them do not even follow what is happening during the class. Then there comes an uncomfortable silence in which students are unsure of what to do next. Considering many conversations with their EFL students, Collie and Slater (1987) state that some students mostly prefer short stories over novels on the grounds that novels include many unknown words and they do not like to look up in the dictionary too often. As novels are long, they find reading the same book for weeks very boring. Some students do not like reading at all, they just want to learn how to speak English (p. 1). Similarly, Ghazali (2008) also claims that student express negative attitudes towards reading, especially poems and novels as they are difficult and complicated. In addition to the negative attitudes, the lessons are mostly teacher-centred which does not give much chance for students properly to show their creativity. As Parkinson and Raid Thomas (2000) state that mostly "the teacher controls in detail what happens in the lesson and this again conflicts with the modern idea that learners should have some control over their own learning" (p. 12). As a result of that the essence of the balance between the emotional and intellectual qualities is lost because learning occurs most efficiently when there is a balance between affective and cognitive which are the emotions and intelligence. ${ }^{2}$ This minimizes student involvement and development of necessary literary skills. It also limits their learning and understanding of the texts. The results of the situation are challenging for both students and the teachers. When reading is difficult, it is not pleasurable for the students. "Students may lose their self-confidence and motivation in learning English if they feel unsuccessful especially because of their low language proficiency levels" (Işıklı and Tarakçıoğlu, 2017). If the fact that even native English-speaking students do not like reading courses is taken into consideration, how can we, as educators, enhance the appreciation and understanding of literature in our EFL classes? All of these problems might be the result of not practicing EFL reading in the

\footnotetext{
${ }^{2}$ For further details see Gardner's Theory of Multiple Intelligences (Gardner, 1999).
} 
right way. This triggers the need to try a new method. This study intends to investigate whether literature circles help students' comprehension of literature and language or not. The learning circle is a significant pedagogical method because it involves multiple intelligences learning, specifically emotional intelligence related to interpersonal and intrapersonal intelligences that increase the acquisition and retention of knowledge. It is a student-centred method in which the students are actively interacting with each other because they all have their roles like the actors in a play.

The main reasons for this study are students' negative attitudes towards reading; their unwillingness to participate in the classroom discussions; and the teacher-centred education which does not give much chance to the students to show their creativity. It is believed that literature circles will make reading more pleasurable and increase the students' desire to read. The fact that every student will have a role in the circle is believed to motivate the students as they all have given different responsibilities in the circle. As a result, their reading and speaking activities will be improved, and their ability to participate in discussion will be broadened.

\section{What are literature circles?}

Recently, there has been increasing interest in integrating literature into language teaching classes, since it provides authentic materials, encourages interaction, and expands language awareness. According to Collie and Slater (1987) using literature in the classroom is very effective as it provides "valuable authentic material, cultural enrichment, personal involvement, and -most importantly- language enrichment" (p. 3-6). There have been many popular ways suggested for the use of literature in language teaching, such the literature circle. In literature circles, small groups of students who have chosen to read the same piece of literature meet and discuss it on a regular schedule.

The history of literature circles in which "a group of students gather together to discuss in depth and share ideas about the piece of literature they read" (Hill, 2007), dates back to early 1980s. A number of teachers and students around the country simultaneously and independently invented the idea of literature circles. Pioneers like Becky Abraham Searle in Chicago and Karen Smith in Arizona began organizing their students into small, peer-led book discussion groups (Daniels, 2006). They aimed at importing the idea of adult book clubs into school atmosphere. Building on the model of adult reading groups, they began translating the structure for younger readers in classrooms and it worked. It turned out that students could pick their own books, form into small groups, and meet regularly to share ideas, feelings, questions, connections, and judgments about books they had read (Daniels, 2002). It is thought that, literature circles held during 40 years have turned out to be successful most of the time. It is also an effective method for EFL students. Of course, the effectiveness of literature circles depends on the students as well in addition to the teacher and the methods or materials $\mathrm{s} /$ he is using. For example, "Especially when working with older literature, the teacher feels almost forced into 'lecture mode', simply telling the learners what they should know and even think, perhaps even translating parts of the text" (Parkinson \& Raid Thomas, 2000, p.12). Accordingly, the reading material should be interesting enough to catch their attention and chapters should not be too long. As a response to some implementation problems of the teacher, Daniels (2006) promoted the use of a tool called role sheets, which assigned students various duties like Questioner, Connector, Illustrator, Word Wizard, and Literary Luminary. He recommended these sheets as a way of showing students how smart readers connect, visualize, and infer. The role sheets also help students capture their reading responses in writing and supply smallgroup discussions with plenty of material to discuss. Though he suggested the role sheets as a temporary use, it became predominant in most of the classes which shows that it is really effective. When students are given responsibilities and roles for the circle, it is a motivating factor for them because it is a studentcentred activity. 


\section{Purpose of the study}

This study is designed to investigate how literature circles can benefit the reading attitudes of EFL students. Specifically, the main aims this study intends to investigate are to discover why teachers choose literature circles as a medium of instruction, to determine how the experience of learning in literature circles affects student attitudes toward reading and to discover whether literature circles help students understand literature. This study intends to investigate and argue about the issues on the responses and findings of the following major research questions:

1. Why do teachers choose to use literature circles?

2. How do teachers' view changes in student attitudes toward reading?

3. How do teachers perceive the role of literature circles in the ability of students to understand literature?

\section{METHOD}

\section{Research Design}

The study used a qualitative content analysis approach. Content analysis is a kind of technique that enables researchers to study human behaviour in an indirect way, through an analysis of their communication (Fraenkel \& Wallen, 2006:483). In the field of educational research, content analysis is widely used to analyse the content of written or verbal communication in an objective manner. After collecting objective information from the literature circle, teachers examine what they have written about their experiences. They discover the outcomes and how they feel about their work. Content analysis is thought to be appropriate for this study because it is analysing the responses of literature circle teachers through the interview data. Interview data was used to determine the effects of literature circles on students' comprehension of literature and language.

\section{Participants}

Participants of this study are three literature circle teachers regularly conducting circles for their college and university students. Literature circle methods of three different educational institutions in different cities in Turkey were investigated and analysed.

One participant of this study was an English Language educator implementing literature circles for EFL students. She was also the dean of preparatory school. As an English teacher, first interviewee is implementing literature circles for college students in reading classes. The other participant of this study was an instructor and reading coordinator from a local university. He is implementing reading circles for extensive reading classes in preparatory program. The last participant was another instructor from another local university. She is also implementing literature circles for reading classes in the preparatory program of the university.

\section{Procedure}

In this study, teachers who are conducting literature circles in their classes were introduced about the research, aims and procedure via e-mail. They were all working in different cities in Turkey. They were also informed about the interview questions prepared beforehand (see Appendix A). Interview questions included the information on personal views, experiences, inference about literature circles and suggestions for the colleagues. Interview data were received as written documents from the teachers who volunteered to share their experiences on literature circles. The data gathered from the interviews 
were transcribed, deeply analysed and compared with some other teacher and student opinions in similar studies for final evaluation.

\section{Data Collection Tools}

Data sources used in this study are the written documents containing interview questions (see Appendix A) and the teacher answers (see Appendix B). Teacher interviews are a significant source for the research to gain first-hand insight about the outcomes of the circles. Through the interviews, teachers were asked about their personal literature circle experiences. They were expected to explain inferences they made on circle setting, materials used, levels, advantages, challenges and special techniques along with their advice.

\section{FINDINGS}

During the study, as it is stated in the introduction, the aim was to investigate and discover the reason why teachers choose literature circles as a medium of instruction and provide proof for the assertion that "literature circles help students understand literature better" along with the question "how the experience of learning affect student attitudes of learning?" In this sense, the findings of the study based on the interview data play an important role in supporting the validity of the theories presented through the whole study related to literature circles.

Data obtained via teacher interviews were analysed to explore meaningful ideas and insights along with a variety of data sources utilized during this study. Each data examined gave a new perspective on the impacts of literature circles. In recent years, there has been an increasing interest in integrating literature into language teaching around the world and literature circles are just one of the methods that developed as a result of this interest. For the sake of providing new insights into the way we teach literature, a large number of researchers and educators have been conducting studies consisting of the circle technique.

\section{Positive Effects}

The overall findings of this study reveal that the educators using literature circles in their classes agree on the point that circles have a positive effect on teaching. Students generally find reading to be boring and difficult, but the idea of literature circle is observed to be fun, exciting and engaging for them. It is not hard to imagine that how difficult it is to read in English when they do not like reading in their own language.

$1^{\text {st }}$ interviewee stated that, thanks to literature circles almost all of the students began reading a whole novel in English for the first time. Giving students a chance to choose the books they will read, makes them much more excited about reading in English. They also become more eager to discuss what they read. There is no use in expecting similar performances from all the students when you make them read the same book regardless of their levels, interests and needs. Circles present educators with a new way to teach all students the same content and skills without regard to their levels, interests, and needs. Freedom of choice helps them acquire ownership, autonomy, and self-confidence. As $2^{\text {nd }}$ interviewee stated, literature circles, the process he called "transformation", positively affects students' motivational acquisition, awareness of responsibility, logical and critical reasoning, and productive interactions. Interviewees also implied that in circles, every student equally participates in the interactive activities by doing their reading and their duties instead of just exploiting the successful friends like they do in the traditional methods. They learn the value of listening and reflecting on the thoughts of others thanks to the circles. They also learn to think more deeply as they read. 


\section{Short Literary Selections}

The analysis revealed that literature circle teachers do not prefer long chapter books and classic literature. This can be considered a good point, as students most probably lose track and get bored in long chapters. Classic literature books may become a torture for most of them. It will be wise to include adventure, fantasy, science-fiction, detective, or modern teenager books for them to choose. These selections will easily attract their attention and arouse the curiosity in them. The more they like what they are reading, the more they willingly adapt to the circle. The system developed by $1^{\text {st }}$ interviewee and her colleagues as a precaution against the possibility of lost or destroyed books can be adapted by many teachers. She claimed that they collect a deposit from the parents at the beginning of the year. If students return books at the end of the year, they can get back the deposit. If not, teachers use the deposit to buy a new one via the internet. Teachers agree that, if the books are chosen carefully and as long as their interests are kept alive, literature circles can be appropriate for all age groups.

\section{Role of the Teacher}

Considering the fact that literature circles are a student-centred method unlike traditional teachercentred methods, interviewees were asked about their roles in the circles. The analysis showed that, teachers are involving in monitoring, assessing, and guiding students whenever they need, help with sample lessons to model the roles and expectations; asking stimulating questions to keep them on track; grouping the students; or preparing a book list for them to choose. As a result, students have more responsibilities to make the class atmosphere more interactive.

\section{Different Learning Styles}

Interviewees also emphasized that literature circles present alternative, effective learning for student who have different learning styles, interests, and needs. Most importantly each one of them has different roles and duties in the circle which can be changed in every new circle or every week for equal participation. These roles and duties give them a chance to do different kinds of activities to show their talents. $1^{\text {st }}$ interviewee mentioned that after books are introduced to the students, they write their 1,2 and 3 choices out of 5 on a ballot, then the top-voted book is chosen. She uses choice boards with many options to demonstrate their learning. Those choices are changed in each unit to give them more opportunities. She also mentioned that they could write and perform a song about a character from the book, or even create a multimedia book trailer on their computer. It all depends on the students. $3^{\text {rd }}$ interviewee added that they watch the movie of the book if there is any and comment on it by comparing the differences. She also mentioned that her students like competitive activities such as comparing their cultures with other cultures based on the book. As understood from the examples, literature circles give many opportunities for students to use their imagination, and to create and present their talents without dampening their creativity, as in traditional methods.

\section{Evaluation}

For the evaluation process, $1^{\text {st }}$ interviewee claimed that they are using circles in conjunction with more traditional approaches for students to express what they are learning about theme, characterization, and plot in open-ended questions. She also emphasized that they collect and assess the role sheets, and give mid-novel and end of novel quizzes to be sure everyone is involved equally in the process. $3^{\text {rd }}$ interviewee also asks instant questions or she may test their memory by writing phrases or sentences from the chapters on the board. The students identify who said it. This can be a useful activity for the students. Brainstorming will trigger their memories and this will most probably end up in a natural conversational atmosphere. She also added that she gives a plus for each correct answer to be used as their participation 
grade. Giving a plus for correct answers is another effective method to keep the student focused on the process. The students, even the shy ones, become willing to participate and share their ideas to be rewarded. Different from the other interviewees, $2^{\text {nd }}$ interviewee expressed that his students present written documents containing their personal impressions about the books with a vocabulary task. He believes that this reminds the students of their responsibilities and positively affects the learning process and motivation.

\section{Teacher vs. Student-Centred}

In the light of the research data it is concluded that, there may be some difficulties while switching from teacher-centred setting to student-centred setting and it may become a time-consuming process until the students get used to the circle atmosphere. Lack of interest in reading based on wrong book of choice, shy students fear of doing something wrong, or the students who try to speak in Turkish can be another challenge, however it is a quite natural situation. There should be a trial and error period.

\section{Advice for Colleagues}

Looking at the overall findings, it can be said that creating a student-centred environment and organizing the schedule in a proper way should be the first priority of the teacher. Every detail in the circle should be modelled step by step until students get used to the roles and the rules, even though it can take some time. If possible, they can watch a few circles to observe and comment on it. More specifically $1^{\text {st }}$ interviewee noted that she uses a fishbowl technique at the beginning to model the circles. One group performs their circle, while the other group takes notes and evaluates. Having students to record their circles and uploading to internet is also a good idea for making sure they only speak in English during the process. She also emphasized that it also gives a chance for teachers to watch the circles online and assess in their own time. Lastly, $3^{\text {rd }}$ interviewee advised the teachers who will use the literature circle technique for the first time that choosing the first book one stage lower than the students' level will work better, as their level may not be exactly at that level in reality.

\section{CONCLUSION \& DISCUSSION}

Through research and interview data, it can be concluded that the use of literature circles clearly helps students to understand literature better by increasing their desire to read. Research data, parallel to the results of similar studies, provide evidence that students' general attitudes towards reading change positively after taking part in the circles. Enhancing their literacy development by mastering and practicing specific skills, students can also develop better comprehension techniques in the circles that will enable them to use the literature for authentic and meaningful purposes.

Literature circles increase social interaction between the students. They learn from each other. They also teach and help one another through the discussions and tasks. Different from the traditional methods, literature circles promote independent thought. Circles provide students an environment similar to the real life in which they can handle the responsibilities of discussing and understanding the book, inventing activities, finding personal meanings related to the discussion.

One of the main conclusions drawn from this research is that literature circles also provide opportunities for EFL learners to ensure their own understanding by effectively reading, analysing, and discussing the books. Implementing circles is also an effective way to increase students' social skills that will lead to enriched learning. Students become more interested in reading when they have book options. Circles give students self-confidence and the feeling of empowerment which make them more willing to talk and share their ideas. They really enjoy the literature circles and become excited about books, as they have more control over their learning. Results of Bedel's (2011) research reveal that literature circles can provide an exciting way to promote student engagement in extensive reading by means of cooperative 
learning and collaborative work. Literature circles also bring excitement and energy into the language classroom, promoting reading for enjoyment different from ordinary classroom instructions. Another study supporting Bedel's findings was conducted by Avcl et al. (2011). His research shows that the literature circle is an effective method for students to adopt reading comprehension skills. He emphasizes that if such an increase is achieved in just one reading, when the method is constantly used, especially with low-skilled students, they can reach the level of high-skilled students.

The opportunity to choose the books they will read encourages students to show their abilities. The circle atmosphere motivates all students to participate equally in discussions, even the ones who are generally unwilling to talk. The natural, small- group setting of the circles makes them feel more comfortable while speaking. Each student has more time to comment and share ideas. In her analysis, Sanchez (1999) reports that literature circles are one key to successful development of English oral language for second language learners (as cited in Bedel, 2011).

As might be expected, thanks to literature circles, students adapt positive reading habits. They understand the books they read, and they can remember every detail in books weeks later. As they enjoy themselves throughout the process, they generally continue reading books in their routines. In his study, Baştuğ et al. (2011) reports that the literature circles method improved the reading comprehension skills of students who had low level reading comprehension. He also emphasizes that his students liked reading books by performing different tasks, discussing, and cooperating with their friends over a period of time. They remembered the book they had read with all the details, even two weeks later.

The role of the teacher, which is another aspect in literature circles, is to facilitate and provide guided practice without dominating the students. The success of the circles depends on the country, students, setting, background, and materials. However, the effectiveness of this method depends mostly on the teacher's motivation and organization in creating a collaborative learning environment without using a mechanical structure. Otherwise, students will just do what they have to and nothing more. Most importantly, materials, activities and roles should be suitable and adapted to age group, language levels, and specific skills.

One other consideration that emerged from this research is the importance of modelling the process to show students the components of literature circles. Students can watch an experienced circle group to learn how to engage in their roles; how to think critically; how to develop questions; how to find key events; and relate them to personal experiences, until they are independently able to do it. Research data supports the idea that the teacher needs to model and guide to open the way for an authentic peer discussion atmosphere for the students, even if the process requires time, patience, and consistency.

To conclude, the encouraging results lead us to think that literature circles are a promising method which increases student motivation and enhances understanding and appreciation of literature through choices. Any teacher, at any grade level, with any content, can adapt and modify circles to their teaching. As educators, we need to change our traditional teaching techniques and literature circles are worth trying.

\section{Limitations of the Study}

Although the findings of the present study supported the positive contribution of literature circles to students' comprehension of literature, some limitations should be considered. The most important limitation that needs to be acknowledged and addressed regarding the present study is the time constraints. The study is a content analysis to provide enough evidence on how useful literature circles are for the students. As a result of this, a larger number of teacher interviewees from a wider range of schools might have created more reliable results. However, limited time and the heavy workload of the 
teachers, to some extent, affected the research process. Another limitation is the fact that as literature circles are not a widespread method in Turkey, there are limited numbers of educational institutions professionally implementing circles.

\section{Recommendations for Future Studies}

Based upon the information and the results collected during this study, future studies can examine the suitability of literature circles in different class levels, different groups and even different courses in detail. Results and findings can provide teachers with strategies that can be used in small group literature circles to assist students in appreciation and understanding of literature. More studies are needed in Turkey to evaluate strengths and weaknesses of the use of literature circles, as this method has begun to be applied in recent years in Turkey. More teachers and educators interested in the subject should experiment with similar studies and organize more literature circle groups in university and college settings to provide further evidence for the advantages of literature circles. The circle technique is needed to be developed in each time for a better learning environment. Considering the developments of technology, exploration of the benefits of online literature circles by implementing a circle into the digital world, creating a Facebook club, a forum, or a blog will also help to demonstrate the advantages of literature circles.

\section{References}

Avcı, S., Baysal, N., Gül, M. \& Yüksel, A. (2011). Impact of literature circles on reading comprehension skill. Sempozyum: 1. Uluslararası Ĕgitim Programları ve Öğretim Kongresi, Eskişehir.

Baştuğ, H., Avcl, S. \& Yüksel, A. (2011). Cognitive and affective contributions of the literature circles method on the acquisition of reading habits and comprehension skills in primary level students. 1st International Conference on Foreign Language Teaching and Applied Linguistics, Sarajevo.

Bedel, O. (2011). Literature Circles in EFL: How they stimulate the social interaction. Retrieved December 6, 2018 from http://eltdigest.com/literaturecircles/

Collie, J. \& Slater, S. (1987). Literature in the Language Classroom: A Resource Book of Ideas and Activities. Cambridge, UK: Cambridge University Press.

Daniels, H. (1994). Literature Circles: Voice and Choice in the Student-Centered Classroom. National-Louis University. York, ME: Stenhouse Publishers.

Daniels, H. (2002). Expository text in literature circles. Voices from the Middle, 9 (4), 7-14.

Daniels, H. (2006). What's the next big thing with literature circles? Voices from the Middle, 13(4), 10-15.

Demiröz, H. (2010). Reading strategies employed by ESL/EFL students. Cumhuriyet Üniversitesi Sosyal Bilimler Dergisi. 34 (2), 81-86.

Fraenkel, J. R. \& Wallen, N. E. (2006). How to Design and Evaluate Research in Education (6th ed.). McGraw Hill.

Gardner, H. (1999). Intelligence Reframed: Multiple Intelligences for the 21st Century. New York, NY, US: Basic Books.

Ghazali, S. N. (2008). Learner Background and their Attitudes towards Studying Literature. Malaysian Journal of ELTResearch. Vol. 4, 1-17. 
Hill, B. C. (2007). Literature circles and response. Proceedings from Nesa Conference '07. Greece. Retrieved December 20, 2018 from http://bonniecampbellhill.com/Handouts/Handouts/NESALitCircleHandoutAthens07.pdf

Işıklı, C. \& Tarakçıoğlu, A. Ö. (2017). Investigating problems of English literature teaching to EFL high school students in Turkey with focus on language proficiency. Journal of Language and Linguistic Studies. 13 (2), 82-95.

Parkinson, B. \& Reid Thomas, H. (2000). Teaching Literature in a Second Language. Edinburgh: Edinburgh University Press.

Tevdovska, E. S. (2016). Literature in ELT setting: Students' attitudes and preferences towards literary texts. Procedia - Social and Behavioral Sciences. 232: 161 - 169.

\section{Appendices}

\section{Appendix A: Teacher Interview Questions}

- What caused you to begin the use of literature circles?

- What are the advantages?

- Can you give me an example of a literature circle setting you have used and explain how you used it?

- What kind of literature did you use?

- Do you incorporate a multiple intelligence approach?

- How do the students' attitudes toward literature change?

- How do you determine if the students understand the literature in literature circles more than a traditional approach?

- Have you tried traditional approaches to teaching literature? Which ones?

- Do you think literature circles are appropriate for all age groups?

- What challenges, difficulties have you encountered with the use of literature circles?

- Describe how you made the literature selections for the literature circles?

- Do certain kinds of literature choices work better than others?

- Are there any literature selections you would not include in a literature circle?

- Describe your role as a coordinator of literature circle?

- How do you train your students to participate in a literature circle? 
- What adjustments do you make in the literature circle training format for language skill level?

- Do you have suggestions for instructors with regard to evaluation of student performance?

- Is there anything you did or would have done differently with this particular group of students?

- What did you learn about this group of students with regard to the literature selection that you did not know before literature circle sessions?

- What advice do you have for instructors who will use the literature circle technique for the first time?

\section{Appendix B: Teacher Interviews}

\section{Interview I}

\section{What caused you to begin the use of literature circles?}

We found that our previous approach to using novels with EFL students was not working. Within the high school preparatory year program, we have a range of students from absolute beginner to advanced English levels, and having all the students read the same book wasn't working. It used to be "The Giver." It was too easy for the highest-level students and the lowest level students were having to look up every other work because it was new vocabulary.

\section{What are the advantages?}

Literature circles allowed us to teach the same content and skills, while differentiating for student English level and interest. By allowing students to choose which one of the books they wanted to read, students had more ownership and autonomy during the process. Student engagement was greatly increased using reading circles. Also, because we had so many different novels being read, there were more students reading the book instead of the SparkNotes!

\section{Can you give me an example of a literature circle setting you have used and explain how you used it?}

In the high school preparatory English program, we have one section of the course specifically teaching reading skills. It is 8 periods a week. We use literature circles in this class. We have about 30 novels in our literature circle list, and 6 copies of each novel which consist 1 teachers copy, 5 student copies. After clearly outlining the purpose of reading circles, the reading teacher introduces each literature circle role one at a time and guides the student through practicing completing that role as a class while reading a short story. After each role has been modelled, the teacher presents the 5 novel options for that unit. Students write their 1, 2, and 3 choices on a ballot and the teacher then places them into groups of no more than 5 , trying to give them their top choice while also considering group dynamics. Then students create a reading calendar together, counting out the number of days and pages. Students read mostly at home, although we also have SSR time of about 15 minutes a day. Students spin for a role each week, complete either at home or in class, and complete the literature circle at the end of the week. Sometimes in the classroom, sometimes outside with one student recording it on their smartphone and uploading the video to YouTube for the teacher to watch later. This continues with one literature circle a week, different roles for different students each week, until the novel is finished. 


\section{What kind of literature did you use?}

The novels are all at a grade 9-12 interest level, but the reading level ranges from lexile 3.4 to 8.4. We use scholastic book wizard to find appropriate titles. We use all sorts of YA novels, all written within the last 10 years, no classic literature.

\section{Do you incorporate a multiple intelligence approach?}

Yes, all of our assessments are designed to appeal to multiple intelligences. Students have choiceboards with a number of options on how to demonstrate their learning. They could write and perform a song about a character from the book, or create a multimedia book trailer on their computer. There are many choices and the choices change each unit.

\section{How do the students' attitudes toward literature change?}

Almost all our students say this is the first time they've actually read a whole novel in English. Especially for our lower-level learners, they don't think they can do it at the beginning, and they amaze themselves about how much they improve over the course of the year. By the end of the year, even absolute beginners are reading 200+ page novels in English. Students also tell us that getting to choose what they read makes them much more excited about reading in English.

\section{How do you determine if the students understand the literature in literature circles more than a traditional} approach?

As I mentioned, we use choiceboards for our larger projects so students have a range of ways to express their learning. Teachers also collect and assess all the role sheets to ensure that every student is doing their reading and their roles and not relying on the strong students to tell them what is happening in the book. Teachers also give mid-novel and end of novel quizzes that have short answer and open-ended questions that ensure students are accountable for the reading and can express what they are learning about theme, characterization and plot in a more traditional way.

\section{Have you tried traditional approaches to teaching literature? Which ones?}

Last year, teachers in the reading course used only the literature circle method. However, we found that there were some gaps because the students were never all reading the same thing, and the teacher couldn't guide the class through the process of interpreting literature and reading. So this year, teachers in the Reading course are using literature circles in conjunction with more traditional approaches. All students have a "Discovering Fiction" short story anthology that is designed for EFL learners, and it includes a short story, vocabulary, comprehension and traditional reading instruction. Teachers use this for whole-class instruction to introduce a concept, say plot development, while all students read the same story. After they learn the concept, they apply it to their individual novels for literature circles.

\section{Do you think literature circles are appropriate for all age groups?}

I think literature circles are most appropriate for the grade 6-10 range. It requires a level of personal accountability and responsibly to work independently of the teacher. Also, at the higher levels, English courses at our school move towards classic literature and Shakespeare, so the classroom must be more teacher-centric. 


\section{What challenges, difficulties have encountered with the use of literature circles?}

It took us a little trial and error to find out how best to use them in the curriculum. As I mentioned, we now use them as one component of our reading course, not the entire course. We also had to come up with a system for when students lose or destroy their novels. We now collect a deposit from parents at the beginning of the year, which they get back at the end of the year if their student returns all the novels. If not, we use their deposit to buy a quick replacement novel from Amazon. We had problems with students using Turkish while completing their literature circles. Whenever the teacher was near, they would use English, but then when the teacher walked to another group, the first group would switch back to Turkish. In order to combat that, we use a few techniques, a fish bowl technique at the beginning, where one group performs their literature circle, while the other groups take notes and evaluate. Then we also turned to the idea of recording the literature circles which has been great for making sure students speak only English while completing their circles. It also gives a chance for teachers to watch the circles online and assess in their own time.

Describe how you made the literature selections for the literature circles?

As I mentioned earlier, teacher suggestions and scholastic book wizard.

\section{Do certain kinds of literature choices work better than others?}

Yes! We removed a few novels from last year's list that were not popular. Now we have a mix, some fantasy like The Graveyard Book, The Warrior Heir, 100 Cupboards; some girly chick-lit like Confessions of a Teen Nanny, Vampire Kisses, If I Stay; some adventure like War of the Eagles, Great Wide Sea; and some modern coming of age like Perks of Being a Wallflower, It's Kind of a Funny Story, Mercy on These Teenage Chimps.

\section{Are there any literature selections you would not include in a literature circle?}

We took out all the Meg Rosoff books as students did not like her! Also, I don't think classic literature would work well for the way that we use literature circles

\section{Describe your role as a coordinator of literature circle?}

I'm not teaching Reading this year, but last year my role was to 1. Choose great books. 2. Introduce the concept with energy. 3. Clearly model the roles and the expectations 4 . Set clear guidelines and rules for the way that literature circles are done 5. Put students in groups that can work well together. 6. Guide students and keep them on track. 7. Monitor and assess.

\section{How do you train your students to participate in a literature circle?}

As I mention, model each role, complete roles as a class using a common short story, eventually model the circle in a fishbowl approach. Lots of scaffolding.

\section{What adjustments do you make in the literature circle training format for language skill level?}

We choose novels based on student language level. Our absolute beginners and low- intermediate classes start with only short stories or Black Cat readers. However, all levels use the same literature circles approach and have the same roles to complete. 
Do you have suggestions for instructors with regard to evaluation of student performance?

I think I covered this above. Lots of choices with choiceboards. Accountability with mid-novel and end-ofnovel-quizzes. Having them record their circles on their smartphones and uploading to YouTube.

Is there anything you did or would have done differently with this particular group of students?

Covered this above.

What did you learn about this group of students with regard to the literature selection that you did not know before literature circle session?

Covered this above.

\section{What advice do you have for instructors who will use the literature circle technique for the first time?}

Leave lots of time for the initial instruction and setup. Students need to be guided very slowly, step by step, through the concepts, the roles, and the rules for circles. Everything should be modelled, even though it can take weeks. Each role should be modelled and they should be guided through completing each role together. The literature circle should be modelled and they should have the chance to watch a few circles and discuss what was good, what was bad, which roles were done correctly, who followed the rules and so on. Do not let the students break off into their own circles until the roles and rules have been hammered into them!

\section{Interview II}

\section{What caused you to begin the use of literature circles?}

Sometimes the lessons became so problematic as the student-talk rate has been reducing gradually and it caused unwillingness for students to discuss about the stories. Almost all of them seemed unwilling to talk, inactive, and unaware of the requirements of expansive reading course objectives. There were just a few students who tried to engage the expected objectives for the course. Enhancing the student-talk was our main goal, so the discussion method has to be moved to the forefront. We wanted to make the class atmosphere more communicative and encourage the students actively to engage in the activities.

\section{What are the advantages?}

Literature circles are not teacher-centred activities. Students are the centre of attention. It gives the students chances to perform interactive activities that increase their self-confidence. Another positive side of the activity is that, different skills such as speaking, listening, reading and writing are all included in the circle. Conversational atmosphere enhanced the students' participation and critical approach to the story which contributes to the students' comprehension and interpretation skills. This kind of studentcentred activity fosters motivational acquisitions. Exchanging ideas helps stimulating the way they think critically, which results in a productive interaction. Students acquire characteristics of leadership and awareness of responsibilities thanks to a shared learning model. Agreements or conflicts tempt the students to more logical and critical reasoning for their implications.

Can you give me an example of a literature circle setting you have used and explain how you used it?

In preparatory English program we use literature circles for expansive reading classes. Task-based reading is considered as the prominent goal. These classes include story books ranging differently in each level. 
This course requires students to read level books or short stories in advance firstly, then discuss the stories during the lessons. Students are given certain tasks and asked to prepare themselves. The tasks in circle activity are delivered spontaneously. There are such roles like the group leader, the character captain, the summarizer, the word master, the climax catcher, the theme expert, the cultural connector and the collector of ideas in the circle. If necessary, the third task is shared by two group members. Students have two weeks to prepare themselves for their roles and the teacher directs them during this period so that they can comprehend the task completely. They have a chance to do feasibility studies and check themselves before the discussion circle day, which encouraged them to take responsibilities more seriously. Students can make use of their papers during the discussion. Discussion circle is the evaluation part of the lesson. I form a task-sheet in order to follow the circle activity. I also construct a simple checklist which focuses on students' activeness, willingness, and awareness of responsibility during the lesson.

\section{What kind of literature did you use?}

Story books, level books, short stories.

\section{How do the students' attitudes toward literature change?}

After implementing discussion circle activity, there were clear transformations. The rates of the students who brought the book, read the book, shared his/her ideas, tried to answer my questions, participated actively in the group activities and asked questions were changed in a positive way. Circles decrease the passiveness and unwillingness of the students. Students seem so excited, ready and eager to discuss the story. The class atmosphere becomes very interactive. The impressive thing is that the students begin talking more than that of the teacher. As the teacher, you only direct them to focus on the main or turning points of the story and ask stimulating questions. There is always a sharp difference between the first lesson and the last one. The discussion atmosphere becomes interactive and stimulating.

\section{How do you determine if the students understand the literature in literature circles more than a traditional approach?}

Students present a one-paragraphed written document which contains their personal impressions about the book, a vocabulary list containing fifteen unknown words from the story within their own sentences. Students interactively make great efforts to answer the teacher's questions, and start asking their own questions. They become aware of their responsibilities. This task-based activity positively affects the learning process and students' motivation. Although they even seemed unwilling to bring their books in the previous lessons, they willingly read, write sentences, discuss the story topics, ask questions and gain my appreciation.

\section{Have you tried traditional approaches to teaching literature? Which ones?}

Before implementing literature circles we were using eclectic methods. Students were asked to read the selected materials and do the required assessments before coming to the class. Then they were discussing the stories by taking notes during the lesson. The lessons were mostly teacher-centred.

\section{Do you think literature circles are appropriate for all age groups?}

My groups consist of adult learners. I have never implemented literature circles for younger students. However, I think literature circles can be appropriate for all age groups as long as it is well-organized. 
What challenges, difficulties have you encountered with the use of literature circles?

Sometimes I am having difficulty in checking students' speaking and correcting their errors since two groups are discussing the topic at the same time.

\section{Describe your role as a coordinator of literature circle?}

Students' discussions among themselves require group accountability and teacher's feedback. As the teacher, I act like a facilitator. My role is to guide them whenever they need, direct them to focus on the main points of the stories and ask stimulating questions.

\section{How do you train your students to participate in a literature circle?}

We are practicing together with the students and doing sample lessons using shorter texts for better understanding for the requirements of the class before we start the real circle activity.

What adjustments do you make in the literature circle training format for language skill level?

Story books and the other materials are chosen according to the level of the students.

Is there anything you did or would have done differently with this particular group of students?

They were asked to prepare their discussion topics through given roles.

What advice do you have for instructors who will use the literature circle technique for the first time? They can prompt their students to discover and then use their skills in the circles by organizing the schedule in a certain system. Students' engagement should be aimed as the first objective. All in all, teachers should deal with stimulating learning involvement and focus on constructing student-centred learning environment. As a teacher, I've been giving up the motto "I know, I teach."

Interview III

What caused you to begin the use of literature circles?

It is a subject in our university.

What are the advantages?

Our students can listen to the story in the classroom. They share their ideas with their friends. They do different duties for each book.

Can you give me an example of a literature circle setting you have used and explain how you used it?

Students read some chapters at home or listen to them in the classroom then the teacher asks some words and comprehensive questions to them and gives a plus for each correct answer. These pluses are used for their participation grade. Or, students are divided into groups. They have different duties for each book. They read some chapters at home and prepare their parts at home, then present their parts in the classroom. For example, if they are the word masters, they choose the most important words of those chapters and tell the class why they chose them. Each group has one-word master, one connector, one summarizer, etc. 


\section{What kind of literature did you use?}

We try to choose different kinds. For example, adventure stories, love stories, detective stories, etc.

\section{Do you incorporate a multiple intelligence approach?}

The duties they do each week let them do different kinds of exercises. In the classroom activities, they answer the question they prefer. Sometimes we had the chance to watch the video of the book and to comment on it.

\section{How do the students' attitudes toward literature change?}

Our students are not interested in reading. If they listen to the chapters in the classroom, they can't say "no." They need to be forced. We have few students interested in reading. As for their homework, unfortunately, they cheat from other classes' students.

How do you determine if the students understand the literature in literature circles more than a traditional approach?

I write phrases or sentences from that day's chapters on the board. They close their books and they tell who said those.

I ask instant questions. Sometimes they do their reading in the classroom, not at home.

Do you think literature circles are appropriate for all age groups?

If your students like reading and the books are chosen properly, yes.

What challenges, difficulties have you encountered with the use of literature circles? Our main difficulty is lack of interest in reading. If the kind of the book is not interesting for the student, it is also a problem.

Describe how you made the literature selections for the literature circles?

Some teachers read the story books and choose the best among them.

Do certain kinds of literature choices work better than others?

Yes, students love adventure books more than others.

Are there any literature selections you would not include in a literature circle?

I don't prefer books with long chapters.

Describe your role as a coordinator of literature circle?

I make their duties easier for them, I present sample duties.

How do you train your students to participate in a literature circle?

They know their duties beforehand. These duties are explained to them. So, each week they know what to do and how to do. 
What adjustments do you make in the literature circle training format for language skill level?

We choose the books according to their level. We start with stage 1 for A2 level. For example, in A2 level we ask for five words for word masters, ten words for higher levels. They submit their parts as written homework, but in the classroom, they explain orally. We expect their level of speech according to their level.

Do you have suggestions for instructors with regard to evaluation of student performance? Their level determines our expectation. If they are in A2 level we ignore some of their grammar mistakes in writing and speech. We also ignore cultural differences. When they give examples, we accept them all if those examples are related to their duties for that book.

Is there anything you did or would have done differently with this particular group of students?

Two years ago, I had reading circle classes and I gave them quizzes for the books selected that year. I found those quizzes from the publishers' internet page. Also, I wrote words from that day's chapters on different pieces of small papers and they selected the word and make a sentence including information from the story.

What did you learn about this group of students with regard to the literature selection that you did not know before literature circle session?

They like comparing their culture with other cultures. If you do something competitive they enjoy it more.

What advice do you have for instructors who will use the literature circle technique for the first time? Choose your books one stage lower than your students' level. Your second book may be suitable for their level. 